\title{
APPROACH TO EVALUATE COMPLEXITY IN NEW PRODUCT DEVELOPMENT PROJECTS
}

\author{
G. SCHUH, M. RIESENER \& C. MATTERN \\ RWTH Aachen University, Laboratory for Machine Tools and Production Engineering (WZL), Germany.
}

\begin{abstract}
Manufacturing companies respond to the customers' demand for more individualized products and enhanced functionality by increasing product variety and integrating multiple technologies in their products. Consequently, complexity in new product development (NPD) projects increases as more and more interdependencies and framework conditions have to be considered. A systematic evaluation of the parameters that drive the complexity of an NPD project prior to project kick-off would enable project management to identify critical issues up-front and adjust the project setup accordingly. There are several recent studies that analyze project complexity and identify complexity drivers. However, there is still a lack of a holistic approach that helps project managers to analyze the complexity of NPD projects and at the same time derive specific measures in order to adjust project complexity.

This paper presents an approach for complexity evaluation of NPD projects during project preparation. The approach is based on complexity drivers that have been determined through literature research, classified according to their impact on the complexity of NPD projects and influenceability by project management as well as on the analysis in terms of their interdependencies. Through individual assessment of the complexity drivers and through portfolio analysis, the focal points of complexity in an NPD project can be identified. Measures to level complexity according to the company's positioning can be derived from studying the portfolio of complexity drivers taking into account their impact on first order interactions between complexity drivers.

Keywords: complexity drivers, complexity evaluation, engineering, new product development, project management.
\end{abstract}

\section{INTRODUCTION}

Complexity in product development has been the subject of many research activities in the past decades. New product development (NPD) projects show various characteristics that are typical for complex systems. According to Ulrich and Probst, complex systems have multiple elements with a high number of interactions. [1] In an NPD project those elements are, for example, different parts of a component in the developed product, individuals or organizational units working together in the project as well as resources and technologies that are utilized to develop the product. All these elements interact either in a physical way like the components of the product or in a non-physical way like project staff sharing information with each other. Hence, a product development project can be considered as a complex system whose behavior is highly dynamic and whose future conditions are hardly predictable. [2]

Complexity in NPD projects has a significant impact on project performance. Recent studies show that around half the projects in product development are not completed on time and within the budget. [3] A prominent example of project delay and cost overrun as a result of high complexity in an NPD project is the development of the Boeing 787 Dreamliner. [4] Thus, complexity is an economic factor with considerable influence on a project's performance. 
The analysis of an NPD project's complexity has to integrate various perspectives and dimensions. An isolated view on only specific elements of an NPD project is insufficient for the analysis of its complexity. An NPD project regarded as part of a system has various interactions with its environment. Therefore, elements from outside of the project's scope, which interact with its internal elements must be considered as well. [5] While elements located within the project's scope can mostly be influenced by the project manager, the elements located in the project environment are normally given and are beyond the sphere of the influence of project management. In order to achieve a balance between internal project complexity and external system complexity the interdependencies between external and internal factors have to be analyzed together. [6]

In this paper, a concept is presented, which allows to evaluate the complexity of an NPD project based on complexity drivers. Complexity drivers in general can be described as influential factors that cause complexity in the project. [7] Complexity drivers are valuable instruments to make complexity measurable and to ensure the practical applicability of the concept at the same time.

The concept aims at finding a balance between completeness of the evaluation on one side and accuracy of the measurement on the other side ensuring, at the same time, its practical applicability during project preparation. With a numerical assessment of the complexity drivers, the overall complexity of the project can be evaluated in different dimensions. This evaluation allows to identify critical elements within the project setup that determine the project's complexity. In addition, the interdependencies between the complexity drivers are analyzed. Complexity drivers with a high reinforcing impact on other drivers should be taken into consideration when defining measures to adjust project complexity.

\section{RELATED WORK}

Sources of complexity in projects were analyzed by a large number of authors, e.g. Baccarini [8] and Williams [9]. An extensive literature review regarding complexity in projects in general was conducted by Geraldi et al. [10]. NPD projects are a particular type of projects that are characterized by significant dynamics and complexity. [11] A framework for the analysis of complexity was contributed by Bosch-Rekveldt et al. based on semi-structured interviews. [12] However, the contributions of these authors aimed primarily at developing a holistic set of complexity drivers. They did not work on a concept for evaluation of those drivers, which could support project managers to identify critical elements of the project setup.

For the analysis of complexity in NPD projects, a holistic set of various complexity drivers is fundamental in order to cover all relevant aspects. Product-related complexity as one of the key underlying elements of project complexity is a fundamental part of this analysis. However, other aspects like organizational complexity have to be considered as well. Backlund presented a definition of organizational complexity regarding an organization's behavior, structure, and processes. [13] Daft presented a measuring method for both organizational complexity in the vertical and horizontal dimensions and spatial complexity that can be quantified by the number of hierarchical levels, the number of organizational units, and their geographical distribution. [14] Yet, these authors do not provide an integrated framework for complexity evaluation including aspects of productrelated complexity as well as organizational complexity.

Some authors developed very accurate measuring methods with focus on particular aspects of NPD project complexity. Schlick et al. developed a design structure matrix-based approach using eigenvalues. [15] Nguyen et al. used the fuzzy analytic hierarchy process to quantify project complexity. [16] The approach of Wang et al. integrated entropy calculation and network theory in order to measure the complexity of organizations. [17] Qureshi and Kang analyzed the interrelations between complexity drivers using structural equation modeling. [18] These aforementioned 
approaches have a common factor in that they provide methods to measure the complexity of NPD projects on a high level of detail. However, they focus on specific aspects of complexity and do not provide a holistic approach to analyze the overall complexity of NPD projects.

Measurements of complexity in other areas were developed by Schuh et al. for global production networks [19] as well as a complexity driver-based approach for the evaluation of complexity in industrial services [20]. Complexity of products was the subject of the work of Sinha [21] Even though these approaches address other areas of application, parts of them can be applied to complexity evaluation of NPD.

This paper intends to present a concept that integrates the advantages and disadvantages of the aforementioned approaches with a holistic set of classified complexity drivers and an evaluation with medium accuracy to ensure practical feasibility of the approach in the early phase of project preparation.

\section{APPROACH TO EVALUATE COMPLEXITY IN NEW PRODUCT DEVELOPMENT PROJECTS}

The approach to evaluate complexity is presented in three sections. First, the overall framework to classify and evaluate complexity drivers is introduced. Then, the analysis of interdependencies between the complexity drivers based on an influence matrix is proposed. On this basis, complexity drivers with high strength of influence and influenceability are identified. The overall framework is an appropriate tool to visualize the effects of a shift in the rating of complexity drivers.

\subsection{Framework for evaluation of complexity using complexity drivers}

Complexity in NPD projects is a phenomenon that is difficult to determine. According to Bliss, there are exogenous and endogenous complexity drivers. Exogenous drivers characterize the complexity of the environment and endogenous complexity drivers describe the complexity of the interior of the project. [22] Referring to NPD projects, complexity drivers are classified into three groups. Complexity drivers describing complexity emerging from inside the project build the first group. In the second group are drivers located inside the company but outside the project. The third group contains drivers within the environment of the company, which can also have an impact on the complexity of the NPD project.

A thematic categorization to facilitate complexity analysis was developed in addition to the structuring by their localization in the project environment. For this purpose, the categories Organization, Product, Resources, and Technologies were defined to categorize the complexity drivers. For each of the categories, complexity drivers have been determined through literature review and complemented by own experience from accompanied development projects. Figure 1 shows the developed framework with these four categories.

The category Organization contains drivers that describe the interactions of an organization with its environment like public authorities or suppliers. Furthermore, the drivers characterizing the elements of the company's organization as well as the project organization are included in this category, e.g. organizational units. [23] The category Product contains complexity drivers that evolve from the product's perspective like market requirements or variety of functions. [24] Especially, a modern structure of the product program in a modular product platform causes additional complexity due to high interdependencies between modules and components. [25] The category Resources includes complexity drivers related to human, material, and financial resources. The availability of resources may have a significant impact on a project's performance. [3] Finally, the category Technologies covers drivers relevant to the technologies that are in use in the product being developed in the 
considered project. For example, using technologies with low experience may also result in additional difficulties in project execution. [26]

The framework allows to arrange the complexity drivers depending on their sphere of influence in a shell model. The drivers located in the inner circle are drivers from the inside of the project. Drivers regarding the project environment from within the company can be located in the middle shell, drivers from outside of the company are arranged in the outer shell. The identified complexity drivers were classified into the framework as shown in Fig. 1.

Complexity of a system in general can be measured on the basis of two dimensions multiplicity/ diversity and variability/dynamics according to Ulrich and Probst [1] In order to describe the impact of a complexity driver on the overall complexity of the NPD project, each driver is evaluated through an individual rating, a company specific weighting, and factors describing the complexity driver's impact on the dimensions. [27] The results of the assessment are visualized using the four categories Organization, Product, Process, and Resources in a portfolio as shown in Fig. 2.

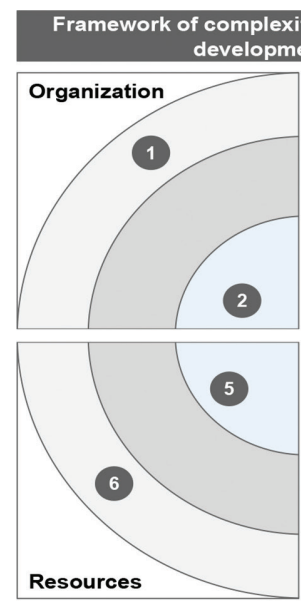

Key: $\times$ Complexity driver $X$
Selected examples of complexity drivers in new prduct development projects
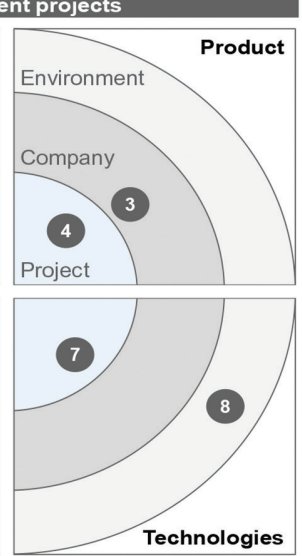

Technologies
(1) Competitor companies

2 Project durance

(3) Addressed target markets

(4) Variety of parts

(5) Project team size

6 Availability of specialized employees

7 Cross-disciplinarity of deployed technologies

8 Diffusion of deployed technologies

Figure 1: Categorization of complexity drivers.
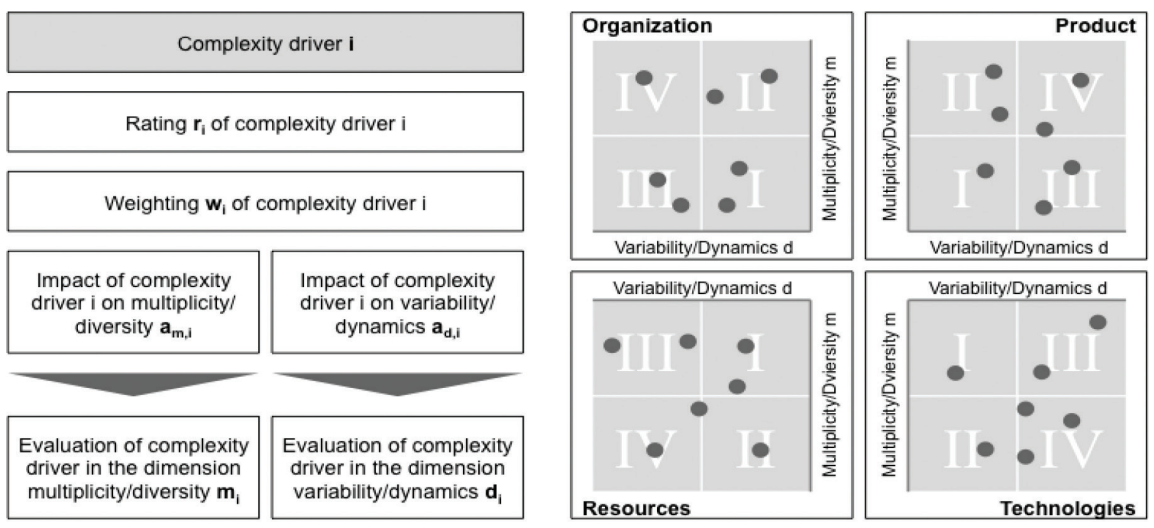

Key: Complexity driver

Figure 2: Visualization of evaluated complexity drivers. 
The presented framework facilitates a large number of different analyses of project complexity. A comparison between the categories or between internally and externally caused complexity is possible. The evaluation of complexity drivers across the four categories allows to investigate cause-effect relationships e.g. between organizational complexity and product-related complexity. A recurrent use of the method allows to investigate how the complexity of a product develops over time. Measures to adjust product complexity should focus on elements with high evaluation. An example for such a measure to adjust project complexity is to reduce product complexity, e.g. number of different components in order to meet the capability of a project organization to handle complexity, e.g. number of project staff.

\subsection{Analysis of interdependencies between complexity drivers}

NPD projects are characterized by versatile interactions. [28] Thus, complexity drivers are also interdependent and their interdependencies have to be taken into account when adjusting the project setup as discussed in the chapter before. The starting point for the analysis of the interdependencies is to resolve the complexity drivers in specific indicators, that are quantitatively ratable. In order to analyze the interdependencies between the complexity drivers, a modeling of the complexity drivers and their indicators making their structure accessible for deeper analysis is required. Figure 3 shows an excerpt of the overall structure with a selection of complexity drivers in the category 'Product'. The influence factor Product Requirements is subdivided into the complexity drivers based on target markets, customer expectations, legal conditions, and others. A specific indicator is assigned to each of the complexity drivers. For example, the indicator Number of relevant laws and norms is assigned to the complexity driver Legal requirements.

This structure of complexity drivers and indicators serves as a basis for further investigation of their interdependencies. The interdependencies between the complexity drivers are determined by using the corresponding indicator. A shift of the rating of one complexity driver, e.g. Target markets, is expressed in a shift of the indicator, e.g. Number of addressed target markets. As the number of addressed target markets increases, the number of documents to be created for product documenta-

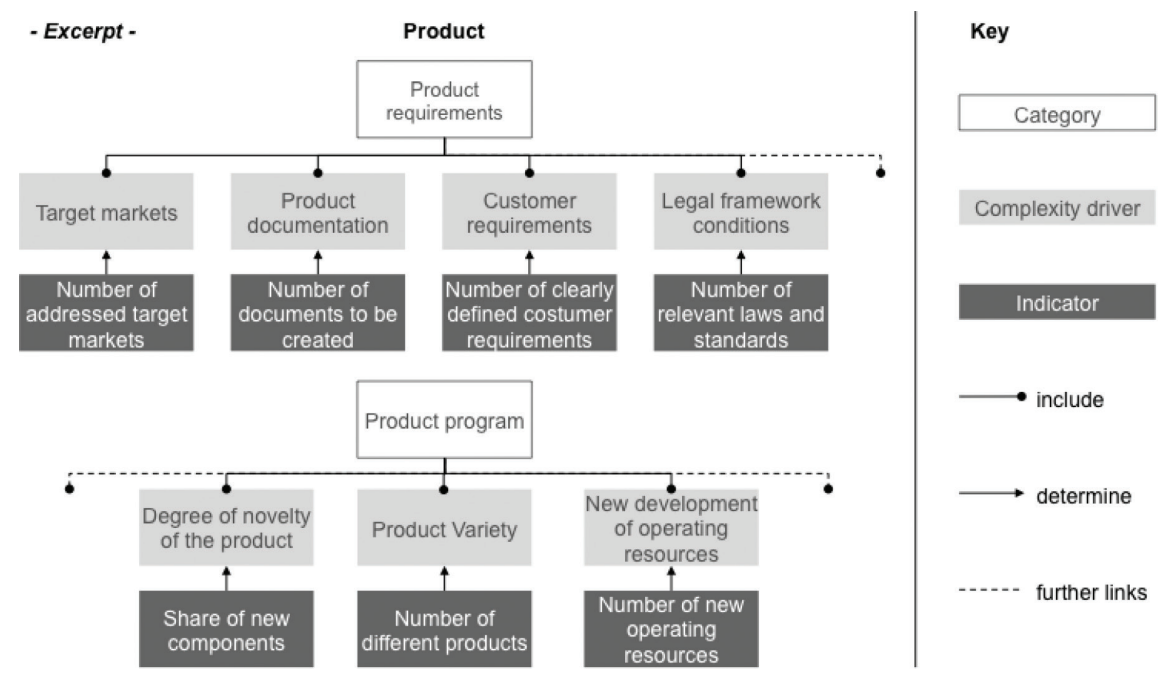

Figure 3: Extract of modeled structure of complexity drivers and indicators. 


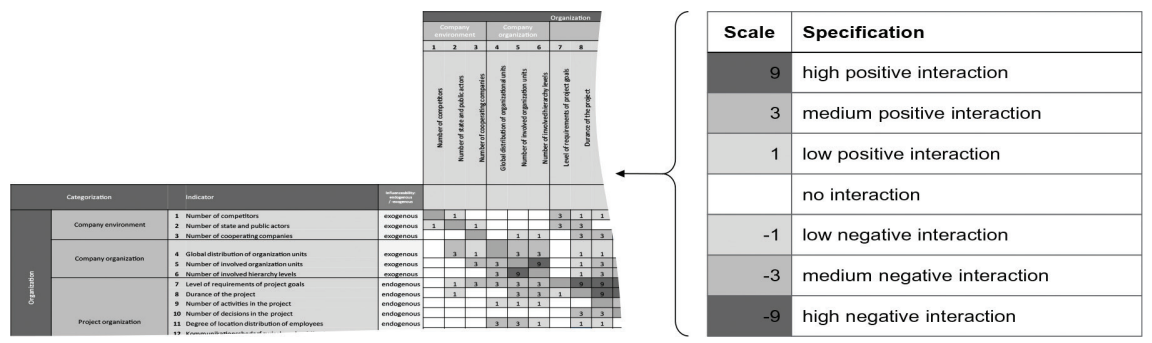

Figure 4: Analysis of interdependencies between complexity drivers.

tion may also increase due to diverse languages. Therefore, another indicator, e.g. Number of documents to be created, changes as well resulting in an shift of the rating of another complexity driver, e.g. Product documentation.

These interdependencies between the elements can be considered as elements of an interconnected system. [29] The interdependencies between the elements of such a system are analyzed by an influence matrix going back to Vester [30] Applied to complexity drivers, these interdependencies between them are analyzed in a matrix as shown in excerpts in Fig. 4.

The indicators of each complexity driver are listed on both axes of the matrix. Each of the cells of the matrix describes the effect of the respective indicator in the row on the respective indicator in the column. The degree and direction of the interaction is detected by a scale from -9 to +9 .

\subsection{Segmentation of complexity drivers in an influence portfolio}

The complexity drivers are segmented depending on their strength of influence $S_{X}$ and their influenceability $\mathrm{I}_{\mathrm{X}}$. According to Fink et al. [31] four segments are differentiated in an influence portfolio: system indicators, independent factors, system levers, and interactive nodes. The influence a complexity driver has on other drivers is indicated by the row total and the influenceability is indicated by the column total in the influence matrix. A high row total $R_{X}$ means that the driver has a strong reinforcing effect on other drivers and, thus, a strong reinforcing effect on the complexity of the system in total. A high column total $C_{X}$ means that the driver is subject to high reinforcing effects by the others. For the strength of influence and the influenceability, the absolute values of each cell $i_{a, b}$ are summed because positive and negative entrances would otherwise cancel each other out and thus falsify the result.

The complexity drivers are classified into the four aforementioned segments depending on the calculated strength of influence $S_{X}$ and the influenceability $I_{X}$ as shown in Fig. 5.

System levers are those complexity drivers that have a high strength of influence $S_{X}$ and a low infuenceability $I_{X}$. As a change in the rating of system levers has a strong impact on multiple other complexity drivers, a system lever or an interactive node is an appropriate starting point for complexity adjustment of a project. On the other side, system indicators have low influence on other complexity drivers but they are strongly influenced by others. Independent factors, however, are characterized by only very few interdependencies. A change in the rating of such a complexity driver will have a low impact on the overall complexity of the project. Interactive nodes have both, a high strength of influence and influenceability. [31]

The effects of shifts in the rating of complexity drivers are again visualized in the introduced framework. The left side of Fig. 6 shows the initial evaluation of complexity drivers in the four dimensions.

In the presented example, three drivers are affected by a fictitious change in the project setup and thus their assessment in the dimensions Variability/Dynamics and Multiplicity/Diversity changes. 


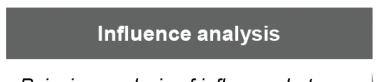

Pairwise analysis of influence between two complexity drivers

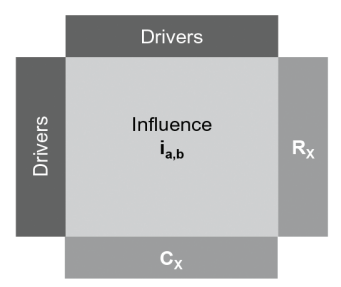

a: $[1 ; n] \quad$ Index for drivers

by row

b: $[1 ; n]$ Index for drivers

$\mathrm{i}_{\mathrm{a}, \mathrm{b}}:[-9,9] \quad$ Influence of driver $\mathrm{a}$ on driver $b$

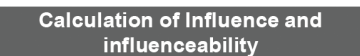

Calculation of Strength of Influence and Influenceability

$R_{X}=\sum_{b=1}^{n}\left|i_{X, b}\right|$

$C_{X}=\sum_{a=1}^{n}\left|i_{a, X}\right|$

$S_{X}=\frac{R_{X}}{\max \left(R_{1}, \ldots, R_{n}\right)}$

$I_{X}=\frac{C_{X}}{\max \left(C_{1}, \ldots, C_{n}\right)}$

$\mathrm{R}_{\mathrm{X}}$ : Row total

of complexity driver $\mathrm{X}$

$\mathrm{C}_{\mathrm{x}}$ : Column total

of complexity driver

$S_{X}$ : Strength of Influence

of complexity driver $X$

$I_{x}$ : Influenceability

of complexity driver $\mathrm{X}$

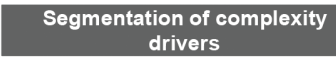

Identification of system levers and

interactive nodes according

to their Strength of Influence and Influenceability

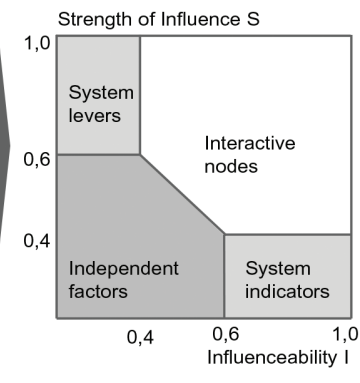

Figure 5: Segmentation of complexity drivers in an influence portfolio.

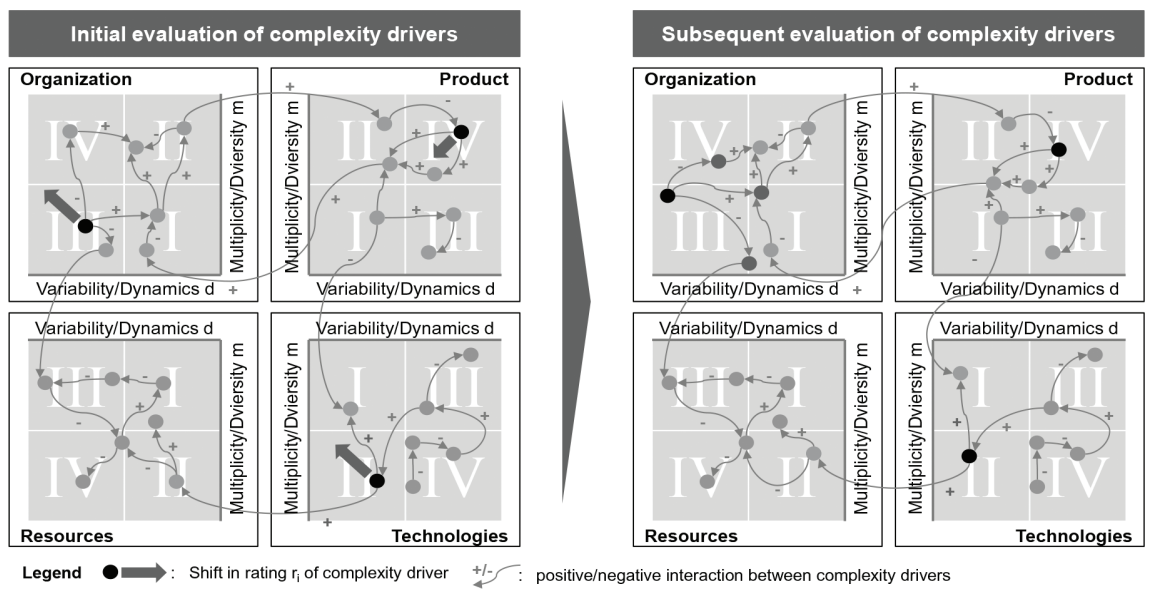

Figure 6: Effects of shift in the rating of complexity drivers.

Due to the interdependencies between the complexity drivers represented by arrows, the assessment of other complexity drivers will change as well. Figure 6 shows the subsequent evaluation taking into account first order interactions between the complexity drivers. The rating of complexity drivers with interactions will increase or decrease according to the sign of the interaction resulting in a corresponding shift within the framework.

\subsection{Application example}

The core elements of the developed concept were applied to a set of complexity drivers. First, approximately 50 complexity drivers were identified through an extensive literature review and classified into the defined categories. Then, a dedicated indicator was assigned to each of the complexity drivers. An excerpt of the resulting structure was introduced earlier in Fig. 3. The influence matrix was created with these indicators for an analysis of the interdependencies. The matrix was 
distributed to and filled out by several senior researchers with multi-year experience in accompanying product development projects in machine and plant manufacturing. For each cell of the matrix, the average was calculated and a merged matrix was created. The entries in the merged matrix were used to calculate the strength of influence $S$ and the influenceability I. With the help of the influence portfolio, system levers and interactive nodes were identified.

The results of the analysis are shown in the following tables. Table 1 shows the eight complexity drivers with the highest strength of influence S. Especially, the aspiration level of project goals and the interdependencies within the product architecture have a high influence on other complexity drivers and determine an NPD project's complexity. Thus, they are 'interactive nodes' which have strong impact on other drivers, but are also highly dependent on others. The drivers legal framework conditions, addressed target markets and variety of technologies used also have a high influence on other drivers but are less affected by other drivers. Thus, they are system levers' This means that narrowing the number of addressed target markets with a project will have a mitigating impact on the overall project complexity.

A selection of complexity drivers with both low strength of influence $S$ and low influenceability I is shown in Table 2. The results of the analysis show that the values for $\mathrm{S}$ and I are remarkable but relatively low compared to the other drivers. The listed complexity drivers like the availability of specialists or competitor companies are relatively less affected by other drivers and have only a low influence on other drivers at the same time.

Table 1: Selection of complexity drivers sorted by descending strength of influence $S$.

\begin{tabular}{lccc}
\hline Complexity driver & S & I & Driver segment \\
\hline Aspiration level of project goals & 1,00 & 0,76 & Interactive nodes \\
Interdependencies within the product & 0,97 & 0,69 & Interactive nodes \\
architecture & & & \\
Project durance & 0,83 & 0,92 & Interactive nodes \\
Functions of the product & 0,81 & 0,75 & Interactive nodes \\
Legal framework conditions & 0,80 & 0,45 & Interactive nodes \\
New development of processes and & 0,75 & 0,72 & Interactive nodes \\
operation resources & & & \\
Addressed target markets & 0,74 & 0,39 & System levers \\
Variety of technologies used & 0,74 & 0,40 & System levers \\
\hline
\end{tabular}

Table 2: Selection of complexity drivers identified as independent factors.

\begin{tabular}{lccl}
\hline Complexity Driver & S & I & Driver segment \\
\hline Availability of specialists & 0,49 & 0,35 & Independent factors \\
Buildings and rooms & 0,25 & 0,52 & Independent factors \\
Capacity utilization of IT systems & 0,27 & 0,41 & Independent factors \\
Competitor companies & 0,49 & 0,39 & Independent factors \\
Job tenure of project staff & 0,43 & 0,50 & Independent factors \\
\hline
\end{tabular}




\section{CONCLUSIONS AND FUTURE WORK}

Increasing variety and enhanced functionality of products lead to increasing complexity in product development. Complexity in NPD requires a deep understanding of multi-layered contexts in the project setup. Handling of complexity is a decisive factor in product development that has a significant impact on the success of a project. This paper presents an approach to evaluate complexity in NPD projects using complexity drivers. Based on an assessment of individual complexity drivers, critical factors that determine project complexity are identified and classified. Interdependencies between the complexity drivers are analyzed using the influence matrix and they are segmented in an influence portfolio. The complexity drivers and their interactions serve as a basis for the analysis of the impact of measures to adjust project complexity in the early phase of a project.

Future work should focus on the systematic identification of measures to adjust project complexity based on the results of the evaluation. The definition of generic measures and their impact on the complexity of a project could be an objective. A promising field for research is complexity in the dimension organization and the linkage between organizational and product-related complexity.

\section{ACKNOWLEDGMENT}

The presented results have been developed within the research project "Complexity evaluation of development projects" (SCHU 1495/87-1) funded by the Deutsche Forschungsgemeinschaft (DFG).

\section{REFERENCES}

[1] Ulrich, H. \& Probst, G.J., Anleitung zum ganzheitlichen Denken und Handeln, Bern: Paul haupt, 1988.

[2] Schuh, G., Produktkomplexität managen: Strategien-Methoden-Tools, München, Wien: Carl Hanser Verlag, 2005.

[3] Lorenz, M., Jentzsch, A., Andersen, M., Noack, B., Waffenschmidt, L., Schuh, G. \& Rudolf, S., The Lean Advantage in Engineering. Developing Better Products Faster and More Efficiently, The Boston Consulting Group \& WZL of RWTH Aachen, 2015.

[4] Kotha, S. \& Srikanth, K., Managing a global partnership model: lessons from the boeing 787 'dreamliner' program. Global Strategy Journal, 3(1), pp. 41-66, 2013. http://dx.doi.org/10.1111/j.2042-5805.2012.01050.x

[5] Kirchhof, R., Ganzheitliches Komplexitätsmanagement: Grundlagen und Methodik des Umgangs mit Komplexität im Unternehmen, Wiesbaden: Deutscher Universitätsverlag, 2003.

[6] Ashby, W.R., An introduction to cybernetics, 1957.

[7] Berens, W. \& Schmitting, W., Controllinginstrumente für das komplexitätsmanagement: potentiale des internen rechnungswesens. Komplexitätsmanagement, pp. 97-110, 1998.

[8] Baccarini, D., The concept of project complexity - a review. International Journal of Project Management, 14(4), pp. 201-204, 1996. http://dx.doi.org/10.1016/0263-7863(95)00093-3

[9] Williams, T., The need for new paradigms for complex projects. International Journal of Project Management, 17(5), pp. 269-273, 1999. http://dx.doi.org/10.1016/S0263-7863(98)00047-7

[10] Geraldi, J., Maylor, H. \& Williams, T., Now, let's make it really complex (complicated). International Journal of Operations \& Production Management, 31(9), pp. 966-990, 2011. http://dx.doi.org/10.1108/01443571111165848

[11] Karniel, A. \& Reich, Y., Managing the Dynamics of New Product Development Processes: $a$ New Product Lifecycle Management Paradigm, Springer-Verlag: London, 2011. http://dx.doi.org/10.1007/978-0-85729-570-5 
[12] Bosch-Rekveldt, M., Jongkind, Y., Mooi, H., Bakker, H. \& Verbraeck, A., Grasping project complexity in large engineering projects: the TOE framework. International Journal of Project Management, 29(6), pp. 728-739, 2011.

http://dx.doi.org/10.1016/j.ijproman.2010.07.008

[13] Backlund, A., The concept of complexity in organisations and information systems. Kybernetes, 31(1), pp. 30-43, 2002.

http://dx.doi.org/10.1108/03684920210414907

[14] Daft, R.L., Organization Theory and Design, Mason, Ohio: South-Western Cengage Learning, 2010.

[15] Schlick, C.M., Duckwitz, S., Gärtner, T. \& Schmidt, T., A complexity measure for concurrent engineering projects based on the DSM. DSM 2008: Proceedings of the 10th International DSM Conference, Stockholm, Sweden, 2008.

[16] Nguyen, A.T., Nguyen, L.D., Le-Hoai, L. \& Dang, C.N., Quantifying the complexity of transportation projects using the fuzzy analytic hierarchy process. International Journal of Project Management, 2015.

http://dx.doi.org/10.1016/j.ijproman.2015.02.007

[17] Wang, Y., Chen, X.H. \& He, X.W., The measurement of complexity of organization coordination network of MSTP. Advances in Information Sciences and Service Sciences, 4(23), pp. 334-342, 2012.

http://dx.doi.org/10.4156/aiss.vol4.issue23.41

[18] Qureshi, S.M. \& Kang, C., Analysing the organizational factors of project complexity using structural equation modelling. International Journal of Project Management, 33(1), pp. 165-176, 2015.

http://dx.doi.org/10.1016/j.ijproman.2014.04.006

[19] Schuh, G., Potente, T., Varandani, R.M. \& Schmitz, T., Methodology for the assessment of structural complexity in global production networks. Procedia CIRP, 7, pp. 67-72, 2013. http://dx.doi.org/10.1016/j.procir.2013.05.012

[20] Schuh, G., Rudolf, S., Breunig, S. \& Lukas, M., Evaluation of complexity in industrial services. Technovation, 2014.

[21] Sinha, K., Structural Complexity and its Implications for Design of Cyber-Physical Systems, Massachusetts Institute of Technology, Cambridge, 2014.

[22] Bliss, C., Integriertes Komplexitätsmanagement: Ansätze und Lösungsmöglichkeiten: Wiss. Ges. für Marketing und Unternehmensführung, 1998.

[23] Ponn, J. \& Lindemann, U., Konzeptentwicklung und Gestaltung technischer Produkte: Systematisch von Anforderungen zu Konzepten und Gestaltlösungen, 2nd edn., Springer: Berlin, Heidelberg, 2011. http://dx.doi.org/10.1007/978-3-642-20580-4

[24] Schuh, G., Gerlach, M. \& Rudolf, S., Methodology for optimizing product differentiation in product ranges. In 2015 Proceedings of PICMET '15: Management of the Technology Age, ed. D.F. Kocaoglu, Portland, Oregon, pp. 1541-1548, 2015. http://dx.doi.org/10.1109/picmet.2015.7273117

[25] Schuh, G., Arnoscht, J. \& Rudolf, S., Integrated development of modular product platforms. Technology Management for Global Economic Growth (PICMET), 2010.

[26] Lindemann, U., Methodische Entwicklung technischer Produkte: Methoden flexibel und situationsgerecht anwenden, 3rd edn., Berlin, Heidelberg: Springer, 2009.

http://dx.doi.org/10.1007/978-3-642-01423-9 
[27] Schuh, G, Rudolf, S. \& Mattern, C., Conceptual framework for evaluation of complexity in new product development projects. In 2016 IEEE International Conference on Industrial Technology (ICIT).

[28] Liso, N.D. \& Leoncini, R., Internationalization, Technological Change and the Theory of the Firm, Routledge: New York, 2011.

[29] Patzak, G., Systemtechnik - Planung Komplexer Innovativer Systeme, Springer-Verlag: Berlin, 1982.

[30] Vester, F, Die Kunst vernetzt zu denken: Ideen und Werkzeuge für einen neuen Umgang mit Komplexität ; ein Bericht an den Club of Rome, 3rd edn., München: Deutscher Taschenbuchverlag, 2003.

[31] Fink, A., Schlake, O. \& Siebe, A., Erfolg durch Szenario-Management: Prinzip und Werkzeuge der strategischen Vorausschau, Campus-Verl: Frankfurt, 2001. 